\title{
O GÊNERO RESUMO ACADÊMICO E AS CIÊNCIAS AGRÁRIAS: UM OLHAR SOBRE A PRODUÇÃO TEXTUAL DE PESQUISADORES GAÚCHOS NA REVISTA CIÊNCIA RURAL ${ }^{1}$
}

DOI: $10.48075 /$ RI.V22I2.24625

Ana Paula Regner ${ }^{2}$

Sabrina Damiani Schmidt ${ }^{3}$

RESUMO: Partindo da concepção de gênero como uma classe de eventos comunicativos, cujos membros compartilham um conjunto de propósitos comunicativos (SWALES, 1990), objetivamos neste artigo identificar como se dá a organização do gênero resumo acadêmico na área das Ciências Agrárias. Para tanto, constituímos nosso corpus de 6 resumos acadêmicos produzidos por pesquisadores gaúchos enviados para os números 3 e 4, do volume 49 da Ciência Rural (UFSM). Posteriormente, analisamos os resumos acadêmicos com base na estrutura esquemática proposta por Motta-Roth e Hendges (2010). A partir disso, nossos resultados apontaram para: i) predominância dos Movimentos 2 e 4: apresentar pesquisa e sumarizar resultados; ii) pouca recorrência no Movimento 1: situar pesquisa; iii) nas recorrências do Movimento 1 , ocorre apenas o Submovimento de generalizações do tópico; iv) no Submovimento do Movimento 2, o destaque é a apresentação dos principais objetivos. Além disso, identificamos falta de linearidade na construção dos resumos analisados, visto que muitos possuem dois Movimentos ao mesmo tempo. Dessa forma, os resultados refletem a tendência de produção de resumos acadêmicos da área referida, nos números da revista analisados.

\section{THE ACADEMIC ABSTRACT GENRE AND AGRICULTURAL SCIENCES: A LOOK AT THE TEXTUAL PRODUCTION OF GAUCHOS RESEARCHERS IN CIÊNCIA RURAL MAGAZINE}

ABSTRACT: Starting from the conception of gender as a class of communicative events, whose members share a set of communicative purposes (SWALES, 1990), we aim in this article to identify how the organization of the academic abstract genre in the field of Agrarian Sciences occurs. To this end, we made up our corpus of 6 academic abstracts produced by researchers from Rio Grande do Sul sent

\footnotetext{
${ }^{1}$ Este artigo é resultado da disciplina "Descrição e análise de gêneros discursivos" ministrada por Francieli Matzembacher Pinton, Doutora em Estudos Linguísticos, docente do Departamento de Letras Vernáculas, da Universidade Federal de Santa Maria. Santa Maria, RS. E-mail: francieli.matzembacher@gmail.com

${ }^{2}$ Acadêmica de Licenciatura em Letras - Português, da Universidade Federal de Santa Maria. Santa Maria, RS. Email: regnerpaulaana@outlook.com

${ }^{3}$ Graduada em Licenciatura em Letras - Português, na Universidade Federal de Santa Maria. Não-Me-Toque, RS. E-mail: sabrinadamiani.12@hotmail.com
} 
to numbers 3 and 4 , of volume 49 of the Ciência Rural (UFSM). Subsequently, we analyzed the abstracts based on the schematic structure proposed by Motta-Roth and Hendges (2010). From this, our results pointed to: i) predominance of Movements 2 and 4: presenting research and summarizing results; ii) little recurrence in Movement 1: situate research; iii) in the recurrences of Movement 1, it does not fall within the Submovement of generalizations of the topic; iv) in the Movement 2 Submovement, the highlight is the presentation of the main objectives. In addition, we identified a lack of linearity in the construction of the analyzed abstracts, since many have two movements at the same time. Thus, the results point to the context of production and circulation of academic abstracts in the area in question, as well as structures articulated with the communicative purpose.

Key words: Critical Genre Analysis. Communicative Purpose. Academic Abstract Genre.

\section{CONSIDERAÇÕES INICIAIS}

A partir da década de 1970, percebe-se um grande interesse pelos estudos de gêneros do discurso, a começar pelos trabalhos de Bakhtin. Apesar da enorme variedade de perspectivas teóricas acerca dos gêneros textuais e discursivos, é comprovável que tais estudos contribuíram, e ainda contribuem, para mudanças significativas no campo de ensino e aprendizagem da Língua Portuguesa, principalmente na Academia, pois a leitura e a produção de artigos e resumos acadêmicos, por exemplo, são instâncias que preocupam professores e alunos universitários.

A preocupação universitária em relação aos estudos dos gêneros textuais e discursivos acadêmicos é tanta que, na Universidade Federal de Santa Maria, por exemplo, há uma disciplina complementar da graduação (DCG) do curso de Letras, intitulada "Descrição e Análise de Gêneros Discursivos", que se preocupa em analisar os gêneros discursivos e textuais, principalmente os acadêmicos. Ao participar dessa disciplina, realizamos estudos sucintos sobre o gênero resumo acadêmico e, assim, analisamos resumos de artigos acadêmicos das áreas da Linguagem (Linguística e Literatura) e também da área das Ciências Naturais (Química), de modo a identificar a estrutura desses exemplares, segundo critérios de Motta-Roth e Hendges (2010). Como produto final da disciplina deveríamos investigar um gênero textual em específico e produzir um artigo. Desse modo, optamos por analisar também o gênero resumo acadêmico dando continuidade aos trabalhos desenvolvidos ao longo da disciplina.

A partir das diversas discussões e reflexões em sala de aula, e levando em consideração o processo de diagramação realizado por uma das autoras na revista Ciência Rural, do Centro de Ciências Rurais, decidimos analisar exemplares do gênero textual resumo acadêmico nas 
Ciências Agrárias. Objetivamos, com isso, identificar como se dá a organização do gênero resumo nessa área específica, isto é, seus movimentos retóricos, por exemplo. Diante disso, escolhemos o periódico Ciência Rural como nosso universo de análise, já que essa revista científica é uma das mais bem-conceituadas da Universidade Federal de Santa Maria e também é reconhecida internacionalmente. A partir dessa escolha e dos diversos critérios de seleção descritos na seção de metodologia deste artigo, coletamos apenas 6 exemplares de resumos acadêmicos, realizando então uma pesquisa exploratória.

Acreditamos que, dessa forma, poderemos investigar minuciosamente diversas instâncias que compreendem esse gênero, de modo que ele se torne mais compreensível em relação aos seus propósitos enquanto atividade social, efetivada em sua organização e padronização textual para a área das Ciências Rurais.

\section{DEFINIÇÕES DE GÊNERO: DA PERSPECTIVA SOCIODISCURSIVA A SOCIORRETÓRICA}

São três os principais conceitos postulados por Bakhtin (2003): língua, enunciado e gêneros do discurso. Para o autor, essas entidades estão diretamente relacionadas, pois auxiliam o bom funcionamento da comunicação. As variedades das esferas de atividades humanas dão origem a vários gêneros do discurso, que resultam em formas-padrão relativamente estáveis de enunciados. Todos nós falamos, escrevemos por meio de gêneros de discurso. Tais gêneros, segundo Bakhtin (2003), nos são dados quase da mesma forma que nos é dada a língua. Assim, os gêneros do discurso sofrem constantes atualizações/transformações, ou seja, o gênero sempre é e não é ao mesmo tempo, isto é, sempre é novo e velho ao mesmo tempo. Isso então explicaria o relativamente estável, pois assim como a comunidade, os gêneros também se modificam para atender as necessidades daquela.

Ao nos referirmos a comunidade, somos levados a concepção de gênero como fato social (BAZERMAN, 2009). Para o autor, os gêneros são fatos sociais sobre os tipos de atos de fala que as pessoas podem realizar e sobre os modos como elas os realizam.

Cada texto bem-sucedido cria para seus leitores um fato social. Os fatos sociais consistem em ações sociais significativas realizadas pela linguagem, ou atos de fala. Esses atos são realizados através de formas textuais padronizadas, típicas e, portanto, inteligíveis, ou gêneros, que estão relacionadas a outros textos e 
gêneros que ocorrem em circunstâncias relacionadas. Juntos, os vários tipos de textos se acomodam em conjunto de gêneros dentro de sistemas de gêneros, os quais fazem parte dos sistemas de atividades humanas. (BAZERMAN, 2009, p. 22. Grifos do autor).

Os gêneros, nessa perspectiva, tipificam muitas coisas além da forma textual, pois são parte do modo como os seres humanos dão forma às atividades sociais. Não muito distantes dessa concepção, encontramos os estudos de Miller (1984), Martin (1985) e Swales (1990).

Miller (1984) postula que uma definição de gêneros retoricamente saudáveis deve concentrar-se não na substância ou na forma do discurso, mas na ação em que ele é usado para realizar. Já para Martin (1985), os gêneros são o modo como as coisas são feitas quando a linguagem é usada para realiza-los. Apesar de todas as teorias supracitadas serem importantíssimas, uma das definições mais amplas de gênero continua sendo a de Swales (1990), conforme nosso entendimento.

Na perspectiva de Swales (1990), um gênero compreende uma classe de eventos comunicativos, cujos membros compartilham um conjunto de propósitos comunicativos. Esses propósitos são reconhecidos pelos membros experientes das comunidades discursivas e, dessa forma, constituem o fundamento lógico do gênero. Esse fundamento modela a estrutura esquemática do discurso, influencia e restringe as escolhas de conteúdo e de estilo. A partir disso, debruçamo-nos na concepção de propósito comunicativo, embasando nosso trabalho nos estudos de Swales (1990), Askehave e Swales (2001), Biasi-Rodrigues (2009), Motta-Roth e Hendges (2010), entre outros.

\section{PROPÓSITO COMUNICATIVO}

De acordo com Bhatia (1993), a relação entre gênero e propósito comunicativo é tão próxima e central que se pode conceber o gênero como um exemplo da realização bemsucedida de um determinado propósito comunicativo, utilizando o conhecimento convencionado de recursos linguísticos e discursivos. Segundo o autor, o propósito comunicativo tem a ver exatamente com aquilo que os gêneros realizam na sociedade, admitindo-se, porém que o propósito de um gênero não é necessariamente único e predeterminado. No conjunto de propósitos comunicativos realizados por um gênero, haverá propósitos específicos ou intenções particulares de certos atores sociais, sejam eles 
produtores de gêneros ou os controladores de sua produção e circulação, como nos casos dos gêneros de mídia, por exemplo, ao lado dos propósitos socialmente reconhecíveis.

Nesse sentido, Askehave e Swales (2001, p. 200) apresentam três razões por que o conceito de propósito comunicativo pode ser produtivamente utilizado na análise dos gêneros. O propósito comunicativo pode: (i) ter um "valor heurístico" como porta de entrada para a melhor compreensão de um corpus de textos; (ii) ajudar a mostrar que os discursos eventualmente são multifuncionais; e (iii) ser utilizado para desqualificar o status de gênero atribuído a certos domínios discursivos, tais como o "economês", às vezes baseados apenas na rotulação de certos registros.

Askehave e Swales (2001) revisitam a pesquisa de Swales da década de 1990 (SWALES, 1990) e concluem que é uma tarefa difícil identificar o propósito de um gênero. Uma das razões dessa dificuldade é o fato de haver múltiplos propósitos comunicativos, que, em determinadas circunstâncias de uso do gênero, não são evidentes à primeira vista. Portanto, é possível encontrar gêneros dotados de conjuntos de propósitos comunicativos (ASKEHAVE; SWALES, 2001).

A maioria dos gêneros possui características que nos permitem reconhecer a que espécie/tipo/grupo pertencem. Essas características frequentemente são relacionadas com as principais funções ou atividades realizadas pelo gênero. Assim, conforme Bazerman (2009), somos tentados a analisar os gêneros selecionando essas reconhecidas características com base em nossos conhecimentos de leituras e de mundo. Nesse sentido, na seção a seguir, apresentamos o referencial teórico que embasou nossos estudos sobre o gênero resumo acadêmico, que foi o gênero textual por nós escolhido como corpus de pesquisa deste trabalho.

\section{GÊNERO RESUMO ACADÊMICO}

A escrita de resumos é uma das propostas mais frequentes no meio acadêmico e pode ser o norte de diversos eventos sociais. O resumo acadêmico, por exemplo, pode antecipar o conteúdo de uma pesquisa que será apresentada em um evento ou até mesmo orientar os participantes de um evento para assistirem trabalhos do seu interesse. Esse gênero pode circular também na função de resumir informações de um texto mais longo (artigos, 
dissertações, teses, etc.), permitindo que os leitores tenham um acesso mais rápido ao texto, uma espécie de panorama geral.

Para Biasi-Rodrigues (2009), os resumos, como formas reduzidas dos respectivos gêneros expandidos (teses, artigos comunicações, etc.) convencionalmente apresentam uma seleção e distribuição de informações que reproduzem a organização retórica do texto-fonte, além de veicularem informações sumarizadas ou encapsularem a existência do texto-fonte, como mencionam Motta-Roth e Hendges (2010).

Em relação as funções sociorretóricas do gênero resumo acadêmico, Biasi-Rodrigues (2009) afirma:

Com a expansão dos sistemas informatizados de armazenamento e transmissão de informações, os resumos ganharam independência e constituem peças genéricas disponíveis a uma audiência que tende a se ampliar dia a dia. Esse fato coloca os produtores de resumo de dissertações e outros gêneros acadêmicos em outros circuitos comunicativos e podem requerer maior atenção para organizar retoricamente as informações de modo a se obter eficácia comunicativa (BIASI-RODRIGUES, 2009, p. 51).

Motta-Roth e Hendges (2010), assim como Santos (1995), baseiam-se no que alguns teóricos chamam de Metodologia CARS, que deu origem ao Modelo CARS (Create A Researsh Space), de Swales (1990). As autoras, baseadas em uma análise de 60 (sessenta) abstracts nas disciplinas de Economia, Linguística e Química, reelaboraram a descrição esquemática do gênero proposto por Santos (1995), conforme Figura a seguir.

Figura 1 - Estrutura esquemática para análise do gênero resumo

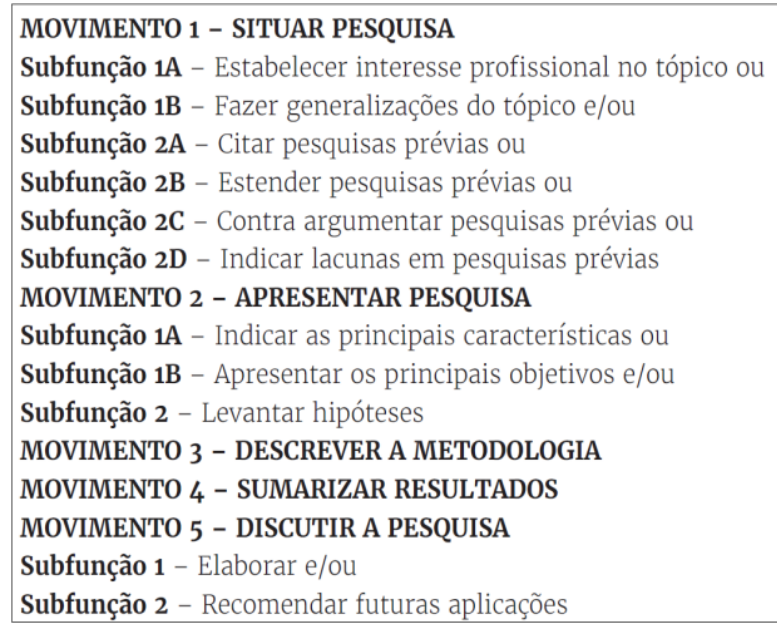

Fonte: Motta-Roth; Hendges (2010) 
Ao apresentarem a estrutura esquemática, Motta-Roth e Hendges (2010) identificam também traços linguísticos, características léxico-gramaticais que tornam esses movimentos retóricos ${ }^{4}$ mais evidentes aos leitores. As autoras destacam, então, verbos no pretérito composto (inglês) e no presente do indicativo, terceira pessoa do singular, voz passiva, sentenças declarativas, sem abreviações, jargões e símbolos (p. 159) como características que podem contribuir para que um exemplar seja protótipo do gênero resumo acadêmico.

Motta-Roth e Hendges (2010) identificam, portanto, cinco principais movimentos retóricos: (i) situar pesquisa, (ii) apresentar pesquisa, (iii) descrever metodologia, (iv) sumarizar resultados e (v) discutir a pesquisa. Além disso, três desses movimentos ainda se dividem em subfunções, cujos próprios nomes dados pelas autoras identificam a função retórica que exercem no gênero, como é o caso do Movimento 5 (Discutir a pesquisa) que é subdivido em duas funções: (a) elaborar e/ou (b) recomendar futuras aplicações.

A seguir, na seção Metodologia, apresentamos nosso universo de análise, o corpus de pesquisa e, também, os procedimentos metodológicos por nós seguidos.

\section{METODOLOGIA}

Analisar diversos textos de um mesmo gênero nos permite vislumbrar como a forma dos textos varia, já que os gêneros podem variar em diferentes áreas ou campos. A diferença dessas formas está relacionada à organização social e à organização de cada atividade em cada campo. Portanto, é essencial pesquisar sobre gêneros, investigar como outras pessoas reconhecem textos, pois esses dados podem oferecer outras visões sobre diferentes significados, intenções e percepções que determinado texto realiza.

Nessa perspectiva, escolhemos nosso universo de análise (subseção 3.1) e selecionamos nosso corpus de pesquisa (subseção 3.2). Além disso, para melhor organizar nosso trabalho, seguimos alguns procedimentos metodológicos (subseção 3.3), tal qual nos aconselha Bazerman (2009).

\section{UNIVERSO DE ANÁLISE}

\footnotetext{
${ }^{4}$ Cf. NWUOGU, 1997.
} 
A Universidade Federal de Santa Maria possui vários periódicos científicos e alguns deles são muito reconhecidos fora do país. Sendo assim, optamos por selecionar uma revista periódica de tal instituição que: (i) obtivesse um Qualis elevado, (ii) fosse reconhecida internacional e (iii) tivesse um grande fluxo de publicações. Desse modo, a revista escolhida como nosso universo de análise foi a Ciência Rural.

A revista Ciência Rural foi fundada em 1971 como Revista do Centro de Ciências Rurais. Mais tarde, foi renomeada como Ciência Rural, como é conhecida até hoje. Indexada na plataforma Scielo, a revista, que atualmente é de fluxo contínuo, publica mensalmente 20 (vinte) trabalhos, entre eles notas e artigos de pesquisadores nacionais e internacionais. A partir de 2016, deixou de ser impressa e, atualmente, está sob forma de circulação on-line, com Qualis A3. Suas publicações consistem em artigos escritos em Língua Inglesa acompanhados de resumos bilíngues (Língua Portuguesa/Língua Inglesa). Tais textos são oriundos de pesquisas das Ciências Agrárias, que se organizam em diferentes áreas: Tecnologia de Alimentos, Fitotecnia, Patologia, Produção Animal, Reprodução Animal, Engenharia Rural, Ciência Florestal, Defesa Fitossanitária, Clínica e Cirurgia, Biologia, Parasitologia, Microbiologia, Ciência do solo, Agronegócio e Extensão Rural. Tal qual essa divisão das Ciências Agrárias, dividem-se as sessões da revista periódica.

\section{CORPUS DE PESQUISA}

Bazerman (2009) afirma que para definir e realizar uma investigação sobre gênero, é necessário enquadrar propósitos e questões para delimitar o seu foco - saber porque se está pesquisando determinado gênero, que perguntas pretendem ser respondidas, etc. -, para, então, definir o corpus de pesquisa, ou seja, os textos ou as coleções que desejamos analisar. O corpus deve ter extensão suficiente para fornecer evidências para que se possam fazer afirmações, mas não deve ser tão extenso a ponto que perca o controle.

Seguindo essa perspectiva, a seleção de nosso corpus de pesquisa foi ancorada por 4 (quatro) critérios. Com o primeiro critério, escolhemos analisar os resumos de artigos do periódico "Ciência Rural”, da UFSM. Sendo assim, deparamo-nos com 49 (quarenta e nove) volumes que, em média, contêm, cada um, mais de 5 (cinco) números. 
No entanto, ao nos depararmos com um grande volume de textos, optamos por um segundo critério de seleção. Sendo assim, coletaríamos resumos de artigos publicados nos dois últimos números disponíveis no site do periódico até a data de início da disciplina. Com isso, coletamos 20 (vinte) artigos no último número publicado, ou seja, 20 (vinte) resumos, e, no penúltimo número, mais 20 (vinte) artigos, isto é, 20 (vinte) resumos.

Mesmo com o segundo critério, nosso corpus ainda prevalecia grande demais para o curto período de realização da análise. Sendo assim, resolvemos acrescentar um terceiro critério. Esse consistia em analisar apenas resumos de artigos escritos por autores brasileiros publicados nos dois últimos números disponíveis no site do periódico até a data de início da disciplina. Tal critério foi embasado no fato de o periódico aceitar trabalhos de autores estrangeiros (ex. chineses, americanos, etc.). Com tal critério, obtivemos um resultado de 14 (quatorze) resumos no último número disponível e 19 (dezenove) no penúltimo.

Visto que nosso corpus de análise ainda continua muito extenso, mesmo com os três critérios comentados anteriormente, optamos por um quarto critério. Esse, por sua vez, consistia em analisar resumos de artigos escritos somente por autores vinculados a instituições gaúchas. Ademais, em consonância com os critérios anteriores, os trabalhos deveriam ter sido publicados nos dois últimos números disponíveis no site do periódico até a data de início da disciplina. Como resultado, obtivemos 2 (dois) resumos no último número escolhido e 4 (quatro) no penúltimo. Desse modo, nosso corpus de análise constitui-se então de 6 (seis) resumos acadêmicos.

Depois da aplicação dos quatro critérios, já com os 6 (seis) resumos acadêmicos devidamente coletados e arquivados, organizamos nosso corpus através de códigos, como descritos na tabela a seguir (Tabela 1 ).

Tabela 1 - Corpus de análise

\begin{tabular}{|ccc|}
\hline CÓDIGO & RESUMO & FONTE (VOLUME/NÚMERO) \\
\hline RACR1 & Resumo artigo 4 & Volume 49, número 4 \\
\hline RACR2 & Resumo artigo 5 & Volume 49, número 4 \\
\hline RACR3 & Resumo artigo 6 & Volume 49, número 3 \\
\hline RACR4 & Resumo artigo 10 & Volume 49, número 3 \\
\hline RACR5 & Resumo artigo 18 & Volume 49, número 3 \\
\hline RACR6 & Resumo artigo 20 & Volume 49, número 3 \\
\hline
\end{tabular}


Utilizamos, então, R para resumo, A para acadêmico, CR para ciência rural (periódico fonte) e, por consequência, o numeral correspondente à ordem de coleta e arquivamento do resumo no corpus de análise. Sendo assim, o primeiro resumo que compõe nosso corpus teria seu código descrito como RACR1, por exemplo. Ressaltamos aqui que, para eventuais consultas, os resumos coletados se encontram em anexo ao final deste artigo.

\section{PROCEDIMENTOS DE ANÁLISE}

Com o corpus selecionado, podemos aplicar ferramentas analíticas com base nos objetivos de nossa investigação. Ou seja, é necessário selecionar ferramentas para investigar as consistências ou variações das características, funções ou relações da coleção para que se obtenham padrões estáveis. Se tais padrões não emergirem, pode ser resultado do corpus não refletir as práticas reais dos usuários ou um fluxo coerente de documentos ou, ainda, o foco analítico pode estar mal colocado.

A partir disso, após a seleção de nosso corpus, analisamo-lo com base no esquema de Motta-Roth e Hendges (2010), que é uma reelaboração da descrição esquemática do gênero proposta por Santos (1995). Para tanto, conforme os apontamentos de Bazerman (2009), utilizamos alguns procedimentos metodológicos, os quais se constituíram de 5 (cinco) passos.

O primeiro passo consistiu na coleta do corpus e na aplicação dos critérios supracitados. O segundo procedimento foi a análise dos Movimentos (MOTTA-ROTH; HENDGES, 2010) do gênero resumo de diferentes seções da revista Ciência Rural. Para a realização desse passo, optamos por definir uma cor de fonte para cada Movimento, conforme apresenta o Quadro 1.

Quadro 1 - Cores de fontes definidas para cada Movimento

\begin{tabular}{|c|c|}
\hline MOVIMENTO & COR DA FONTE \\
\hline M1-Situar pesquisa & Azul \\
\hline M2-Apresentar pesquisa & Vermelho \\
\hline M3- Descrever a metodologia & Amarelo \\
\hline M4- Sumarizar resultados & Verde \\
\hline M5 - Discutir a pesquisa & Laranja \\
\hline
\end{tabular}

Já o terceiro passo consistiu na identificação dos Submovimentos (MOTTA-ROTH; HENDGES, 2010). Assim, o quarto procedimento metodológico foi a comparação dos 
Movimentos das diferentes seções. Por fim, realizamos o quinto e último passo, que consistia nos apontamentos gerais e finais.

A análise, bem como a discussão dos resultados obtidos com os procedimentos metodológicos supracitados pode ser visualizada na seção a seguir.

\section{ANÁLISE E DISCUSSÃO DE RESULTADOS}

A partir da análise de 6 (seis) resumos da revista Ciência Rural (UFSM) de artigos escritos somente por autores vinculados a instituições gaúchas, dos números 3 (três) e 4 (quatro) do periódico de 2019, identificamos, primeiramente, que os resumos pertencem a diferentes seções: Produção de Culturas (RACR1), Ciência do Solo (RACR2), Engenharia Rural (RACR3), Patologia (RACR4), Tecnologia dos Alimentos (RACR5) e Agronegócio (RACR6).

Tabela 2 - Identificação dos Movimentos dos resumos.

\begin{tabular}{|c|c|c|c|c|c|c|}
\hline Resumo & Seção & M1 & M2 & M3 & M4 & M5 \\
\hline RACR1 & Produção de Cultura & & $\mathrm{X}$ & $\mathrm{X}$ & $\mathrm{X}$ & $\mathrm{X}$ \\
\hline RACR2 & Ciência do Solo & $\mathrm{X}$ & $\mathrm{X}$ & $\mathrm{X}$ & $\mathrm{X}$ & $\mathrm{X}$ \\
\hline RACR3 & Engenharia Rural & $\mathrm{X}$ & $\mathrm{X}$ & $\mathrm{X}$ & $\mathrm{X}$ & \\
\hline RACR4 & Patologia & $\mathrm{X}$ & $\mathrm{X}$ & & $\mathrm{X}$ & \\
\hline RACR5 & Tecnologia dos Alimentos & & $\mathrm{X}$ & & $\mathrm{X}$ & $\mathrm{X}$ \\
\hline RACR6 & Agronegócio & & $\mathrm{X}$ & $\mathrm{X}$ & $\mathrm{X}$ & $\mathrm{X}$ \\
\hline
\end{tabular}

Com base na análise desses resumos (Anexos), constatamos que os principais Movimentos identificados foram apresentar pesquisa (M2) e sumarizar resultados (M4), conforme mostra a Tabela 2.

Observamos, ainda conforme Tabela 2, que o Movimento situar pesquisa (M1) é o único que ocorre apenas em três dos seis resumos do corpus, sendo presente apenas nos RACR2, RACR3 e RACR4.

Diante desses resultados, constatamos que o contexto de circulação (periódico das Ciências Agrárias) e de produção (resumos acadêmicos escritos por autores de diferentes áreas) é extremamente relevante para indicar quais os Movimentos são mais pertinentes e, portanto, se mostram mais frequentes. Assim, para a área das Ciências Agrárias, o intuito do gênero resumo seria transparecer os objetivos e apresentar resultados, por isso a predominância dos M2 e M4. 
Conforme Tabela 3, observamos que os Submovimentos do M2 (Apresentar a pesquisa) constitui-se principalmente pela apresentação dos objetivos.

Tabela 3 - Identificação dos Submovimentos do Movimento 2 (M2)

\begin{tabular}{|c|c|c|c|}
\hline \multicolumn{4}{|c|}{ MOVIMENTO 2 - APRESENTAR PESQUISA } \\
\hline Resumo & $\begin{array}{c}\text { Indicar as principais } \\
\text { características }\end{array}$ & $\begin{array}{c}\text { Apresentar os principais } \\
\text { objetivos }\end{array}$ & $\begin{array}{l}\text { Levantar } \\
\text { hipóteses }\end{array}$ \\
\hline RACR1 & & $\mathrm{x}$ & \\
\hline RACR3 & & $x$ & $x$ \\
\hline RACR4 & & $\mathrm{x}$ & \\
\hline RACR5 & $x$ & $x$ & $x$ \\
\hline RACR6 & & $\mathrm{x}$ & \\
\hline
\end{tabular}

A predominância do Submovimento de apresentar os principais objetivos pode também ser relacionada com os propósitos comunicativos desse gênero. Dessa forma, podemos compreender com mais clareza o pensamento de Bhatia (1993), o qual afirma que a relação entre gênero e propósito comunicativo é tão próxima e central que se pode conceber o gênero como um exemplo da realização bem-sucedida de um determinado propósito comunicativo. Tal propósito tem a ver exatamente com aquilo que os gêneros realizam na sociedade, admitindo-se, porém, que o propósito de um gênero não é necessariamente único e predeterminado, como, por exemplo, a função social do resumo acadêmico é apresentar de forma concisa o texto de um artigo, obra ou outro documento, os elementos de maior interesse e importância (SALVADOR, 1978).

Tabela 4 - Descrição dos Submovimentos do Movimento 1 (M1)

\begin{tabular}{|c|c|c|c|c|c|c|}
\hline \multicolumn{7}{|c|}{ MOVIMENTO 1 - SITUAR PESQUISA } \\
\hline Resumo & $\begin{array}{l}\text { Estabelecer } \\
\text { interesse } \\
\text { profissional }\end{array}$ & $\begin{array}{l}\text { Fazer } \\
\text { genera- } \\
\text { lizações } \\
\text { do tópico }\end{array}$ & $\begin{array}{c}\text { Citar } \\
\text { pesquisas } \\
\text { prévias }\end{array}$ & $\begin{array}{c}\text { Estender } \\
\text { pesquisas } \\
\text { prévias }\end{array}$ & $\begin{array}{l}\text { Contra- } \\
\text { argumentar } \\
\text { pesquisas } \\
\text { prévias }\end{array}$ & $\begin{array}{c}\text { Indicar } \\
\text { lacunas de } \\
\text { pesquisas } \\
\text { prévias }\end{array}$ \\
\hline RACR2 & & $x$ & & & & \\
\hline RACR3 & & $x$ & & & & \\
\hline RACR4 & & $x$ & & & & \\
\hline
\end{tabular}


Em relação aos submovimentos do Movimento 1 (M1 - Situar pesquisa), percebemos que, ao situá-la, os resumos apresentam, principalmente, generalizações sobre as temáticas, de modo que, nesse campo de pesquisa, o foco principal não é estabelecer o interesse profissional, nem citar, estender, contra-argumentar e indicar lacunas de pesquisas prévias (Tabela 4).

Conforme revelado na Tabela 3, o Submovimento fazer generalizações do tópico foi o único Submovimento do Movimento 1 (M1 - Situar pesquisa) encontrado nos resumos analisados. Desses resumos apenas os de códigos RACR2, RACR3 e RACR4 possuíam o Submovimento supramencionado. No Quadro 2, podemos visualizar como esses Submovimentos apareceram nos resumos.

Quadro 2 - Submovimento fazer generalizações do tópico

RESUMO RECORTE COM SUBMOVIMENTO
RACR2 $\begin{aligned} & \text { O Rio Grande do Sul possui cerca de } 20 \% \text { da área total de solos de terras baixas, } \\ & \text { propícias para o cultivo do arroz (Oryza sativa) irrigado por inundação. } \\ & \text { Buscando mitigar danos ocasionados com o monocultivo de arroz, novas } \\ & \text { culturas, como o sorgo (Sorghum bicolor) e a soja (Glycine max), têm sido } \\ & \text { cultivadas nestas áreas. Com diferentes qualidades de resíduos culturais, } \\ & \text { espera-se uma alteração na dinâmica da matéria orgânica do solo (MOS) e, } \\ & \text { consequentemente, do nitrogênio (N). }\end{aligned}$

No quadro acima (Quadro 2), destacamos (em negrito) um trecho do resumo RACR3 que podemos classificar como dois Movimentos: i) Movimento 1 (Apresentar pesquisa) Submovimento fazer generalizações do tópico, pois funciona como continuação da generalização do trecho anterior; e ii) Movimento 2 (Situar pesquisa) - Submovimento levantar hipóteses, pois também funciona como uma hipótese levantada pelos autores para o problema citado no trecho antecessor. 
Em relação ao Movimento 2 (M2 - Apresentar pesquisa), constatamos que, além do Movimento 4 (M4 - Sumarizar resultados), é o único Movimento presente em 100\% do corpus analisado, conforme Tabela 1. Sendo assim, identificamos os Submovimentos de M2 presentes nesses resumos e apresentamo-los na Tabela 5.

Tabela 5 - Descrição dos Submovimentos do Movimento 2 (M2)

\begin{tabular}{|c|c|c|c|}
\hline \multicolumn{4}{|c|}{ MOVIMENTO 2 - APRESENTAR PESQUISA } \\
\hline Resumo & $\begin{array}{l}\text { Indicar as principais } \\
\text { características }\end{array}$ & $\begin{array}{l}\text { Apresentar os } \\
\text { principais objetivos }\end{array}$ & Levantar hipóteses \\
\hline RACR1 & & $X$ & \\
\hline RACR2 & & $X$ & \\
\hline RACR3 & & $X$ & $X$ \\
\hline RACR4 & & $\mathrm{X}$ & \\
\hline RACR5 & & $X$ & $X$ \\
\hline RACR6 & & $X$ & \\
\hline
\end{tabular}

Conforme a Tabela 5, o Submovimento apresentar os principais objetivos é o único que aparece em todos os resumos analisados, com exceção do Submovimento levantar hipóteses encontrado no resumo RACR3 - caso mencionado anteriormente -, e no resumo RACR5 quando se lê: "Esses compostos são eletrofílicos e, portanto, podem se ligar covalentemente ao DNA, o que pode resultar em mutagenicidade" (Grifos nossos).

A partir disso, optamos por trazer, no Quadro 3, os trechos que competem ao Submovimento apresentar os principais objetivos.

Quadro 3 - Submovimento apresentar os principais objetivos de M2 encontrados no corpus

RACR1 'Brasileirinha' por dimensões lineares das folhas e testar modelos disponíveis na literatura.

O objetivo deste estudo foi avaliar a influência de resíduos culturais de arroz, soja e sorgo na quantidade de $\mathrm{N}$ em frações físicas da MOS de dois solos de

RACR2 terras baixas, utilizando a técnica de marcação isotópica de $15 \mathrm{~N}$ das culturas e uma incubação por um ciclo de $\mathbf{1 8 0}$ dias em condição aeróbica e mais $\mathbf{1 8 0}$ dias em condição anaeróbica.

O objetivo do presente trabalho foi projetar uma concepção de um sistema mecanizado para o controle das plantas daninhas por meio da utilização de

RACR3 calor, tendo como público alvo agricultores familiares que produzem de forma orgânica.

O objetivo deste trabalho foi relatar um surto de leucoencefalomacia em

RACR4 equinos alimentados com milho verde. 


\begin{tabular}{|c|l|}
\hline RACR5 & $\begin{array}{l}\text { Os objetivos deste estudo foram verificar a ocorrência de álcool furfurílico } \\
\text { (FA) e compostos carbonílicos (acetaldeído, acroleína, carbamato de etila } \\
\text { (CE), formaldeído e furfural) em espumantes e avaliar, pela primeira vez, se o } \\
\text { consumo das amostras em estudo poderia representar risco para a saúde do } \\
\text { consumidor. }\end{array}$ \\
\hline RACR5 & $\begin{array}{l}\text { Considerando condições econômicas, contingênciais e culturais que } \\
\text { interferem na demanda do consumidor, o objetivo desta pesquisa foi avaliar } \\
\text { o grau de importância dessas variáveis na decisão do consumidor brasileiro } \\
\text { de comprar leite fluido. }\end{array}$ \\
\hline
\end{tabular}

A partir do Quadro 3, identificamos, assim como no Quadro 2, a presença de um Submovimento e um Movimento em um mesmo trecho, destacado (em negrito) no resumo RACR2. No trecho destacado, constatamos a presença do Submovimento apresentar os principais objetivos do Movimento 2 ( $\mathrm{M} 2$ - Apresentar pesquisa). No entanto, notamos que o mesmo trecho pode também ser classificado como Movimento 3 (M3 - Descrever metodologia), pois, ao passo que apresenta os objetivos do trabalho, também relata a metodologia seguida para sua realização.

Sendo assim, buscamos com o Quadro 4 exemplificar os M3 (Movimento 3 - Descrever metodologia) encontrados no corpus de análise, mais especificamente nos resumos RACR1, RACR2, RACR3 e RACR6.

Quadro 4 - Movimento 3 (M3 - Descrever metodologia) no corpus de análise

\begin{tabular}{|c|l|}
\hline RESUMO & \multicolumn{1}{|c}{ RECORTE COM MOVIMENTO } \\
& $\begin{array}{l}\text { Foi conduzido um experimento na safra 2015/16 sendo coletas } 500 \text { folhas. } \\
\text { Em cada folha foram mensurados comprimento (L), largura (W), calculado } \\
\text { produto comprimentoxlargura (LW) e determinada a área foliar real (LA). } \\
\text { Depois, } 400 \text { folhas foram separadas para a geração de modelos da área foliar } \\
\text { real (LA) em função da dimensão linear (L, W ou LW) de abobrinha. As demais } \\
100 \text { folhas foram utilizadas na validação dos modelos. Um segundo } \\
\text { experimento foi conduzido na safra 2016/17, no qual foram coletadas } 250 \\
\text { folhas utilizadas na validação dos modelos gerados no primeiro experimento. }\end{array}$ \\
\hline \multirow{2}{*}{ RACR1 } & $\begin{array}{l}\text { Utilizando a técnica de marcação isotópica de 15N das culturas e uma } \\
\text { incubação por um ciclo de 180 dias em condição aeróbica e mais 180 dias em } \\
\text { condição anaeróbica. }\end{array}$ \\
\hline \multirow{2}{*}{ RACR2 } & $\begin{array}{l}\text { Para a realização do trabalho foi empregada metodologia de } \\
\text { desenvolvimento de produtos, a qual pode ser dividida em diferentes fases, } \\
\text { que são compostas por diversas tarefas. }\end{array}$ \\
\hline RACR3 & $\begin{array}{l}\text { Um total de 1.015 consumidores de leite foi pesquisado por meio de } \\
\text { ferramentas não probabilísticas, como rede de contatos de pesquisadores, } \\
\text { bola de neve e amostras autogeradas, em um questionário virtual. Testes não } \\
\text { paramétricos e análises estatísticas univariadas foram aplicados, incluindo o } \\
\text { teste qui-quadrado. }\end{array}$ \\
\hline RACR6
\end{tabular}


Além dos três Movimentos supracitados, identificamos outros dois Movimentos: M4 (Movimento 4 - Sumarizar resultados) e M5 (Movimento 5 - Discutir a pesquisa). Tais Movimentos são trazidos, respectivamente, nos Quadros 5 e 6 a seguir.

Quadro 5 - Movimento 4 (M4 - Sumarizar resultados) no corpus de análise

\begin{tabular}{|c|c|}
\hline RESUMO & RECORTE COM MOVIMENTO \\
\hline RACR1 & $\begin{array}{l}\text { Existe colinearidade entre } L \text { e } W \text { e, por isso, os modelos que utilizam o produto } \\
L W \text { não são recomendados. } O \text { modelo } L A=0,5482 W 2+0,0680 W\left(R^{2}=0,9867\right) \text { é } \\
\text { adequado para a estimação de área foliar de abobrinha 'Brasileirinha'. }\end{array}$ \\
\hline RACR2 & $\begin{array}{l}\text { Aos } 30,180 \text { e } 360 \text { dias de incubação foi quantificado o } \mathrm{N} \text { remanescente dos } \\
\text { resíduos vegetais e destino do } \mathrm{N} \text { proveniente dos resíduos nos dois solos em } \\
\text { frações físicas da MOS }>250 \mu \mathrm{m}, 250-53 \mu \mathrm{m} \text { e }<53 \mu \mathrm{m} \text {. O solo com maior } \\
\text { quantidade de argila+silte recebeu maior quantidade de } 15 \mathrm{~N} \text { dos resíduos, } \\
\text { enquanto que o alagamento do solo após } 180 \text { dias de incubação ocasionou uma } \\
\text { perda do } \mathrm{N} \text { adicionado ao solo pelos resíduos de soja e sorgo. De maneira geral, } \\
\text { foram encontradas maiores quantidades de } 15 \mathrm{~N} \text { na fração }<53 \mu \mathrm{m} \text {, associado } \\
\text { aos argilominerais. }\end{array}$ \\
\hline RACR3 & $\begin{array}{l}\text { Como resultado da aplicação da metodologia obteve-se seis concepções de } \\
\text { máquinas aplicadoras de calor. Após aplicação de ferramentas de seleção } \\
\text { foram escolhidas duas concepções para o processo de otimização, obtendo-se } \\
\text { posteriormente aquela considerada ideal para atender as necessidades dos } \\
\text { agricultores. }\end{array}$ \\
\hline RACR4 & $\begin{array}{l}\text { Dois equinos de três animais apresentaram sinais clínicos neurológicos } \\
\text { aproximadamente sete dias após iniciarem a ingestão de milho verde na fase } \\
\text { reprodutiva (R2, grãos leitosos) com palha e talos, colhido no máximo } 24 \text { horas } \\
\text { antes de ser administrado. A morte ocorreu aproximadamente } 24 \text { horas após } \\
\text { o início dos sinais clínicos. Macroscopicamente havia no sistema nervoso } \\
\text { central áreas multifocais acinzentadas e amareladas na substância branca do } \\
\text { telencéfalo, no hipocampo e no tálamo. Histologicamente observou-se edema } \\
\text { e hemorragia em diversas áreas da substância branca do telencéfalo, que } \\
\text { correspondiam às áreas acinzentadas observadas na macroscopia. Havia, } \\
\text { também, próximo as áreas hemorrágicas, focos de malacia com presença de } \\
\text { astrócitos reativos com abundante citoplasma eosinophilico e algumas células } \\
\text { inflamatórias. Degeneração das paredes dos capilares e tumefação das células } \\
\text { endoteliais também foram observadas. Na análise da amostra de milho pelo } \\
\text { método de colunas de imunoafinidade (VICAM) foram detectados } 2 \text { ppm de } \\
\text { fumonisina. A atividade de água neste cereal, quando o grão ainda está leitoso, } \\
\text { é de } 0,98 \text {, o que predispõe ao crescimento de fungos produtores de } \\
\text { micotoxinas. No presente caso fumonisina foi encontrada nos grãos leitosos no } \\
\text { início da fase reprodutiva (R2), o que sugere que mesmo o milho ainda imaturo } \\
\text { pode estar infectado por Fusarium spp. e não deve, também, ser } \\
\text { administrado aos equinos. }\end{array}$ \\
\hline RACR5 & $\begin{array}{l}\text { CE e formaldeído foram encontrados em baixos níveis }(<1 \mu \mathrm{g} / \mathrm{L}) \text { em todas as } \\
\text { amostras. Acetaldeído, furfural e acroleína também foram encontrados em } \\
\text { baixos níveis }(<1,5 ; 1,4 \text { e } 1,0 \mu \mathrm{g} L-1 \text {, respectivamente) em } 57,71 \text { e } 76 \% \text { das }\end{array}$ \\
\hline
\end{tabular}


amostras. Nas demais amostras, os níveis de acetaldeído, furfural e acroleína variaram de 5,2 a $54,8,10,5$ a 41,0 e 20,3 a $36,7 \mu \mathrm{g} L-1$, respectivamente. 0 álcool furfurílico também foi encontrado em todas as amostras em níveis de 10,4 a 33,5 $\mu \mathrm{g}$ L-1. A acroleína foi o único composto encontrado em níveis suficientes para representar risco à saúde, que ocorreu em $24 \%$ das amostras. $O$ perfil do consumidor interfere com os critérios de seleção na compra de leite fluido da seguinte forma: (a) as mulheres consideram "preço", "origem do RACR6 produto", "recomendação de amigos", "aparência do produto", "ofertas de venda" e "marca" como os condicionantes mais importantes; (b) os jovens, com idade entre 18 e 25 anos, consideram a "origem do produto" um atributo

RACR6 menos importante; (c) consumidores com mais de 45 anos de idade valorizam menos a variável "preço"; (d) os consumidores com renda de até um salário mínimo valorizam as "ofertas de venda".

Quadro 6 - Movimento 5 (M5 - Discutir a pesquisa) no corpus de análise

\begin{tabular}{|c|c|}
\hline RESUMO & RECORTE COM MOVIMENTO \\
\hline RACR1 & $\begin{array}{l}\text { Os modelos que utilizam o produto LW não são recomendados. O modelo } \\
L A=0,5482 W 2+0,0680 W\left(R^{2}=0,9867\right) \text { é adequado para a estimação de área } \\
\text { foliar de abobrinha 'Brasileirinha'. }\end{array}$ \\
\hline RACR2 & $\begin{array}{l}\text { As perdas de } \mathrm{N} \text { devem ser consideradas na adubação nitrogenada para as } \\
\text { culturas sequentes nos sistemas de rotação de culturas com arroz irrigado. }\end{array}$ \\
\hline RACR4 & $\begin{array}{l}\text { Mesmo o milho ainda imaturo pode estar infectado por Fusarium spp. e não } \\
\text { deve, também, ser administrado aos equinos. }\end{array}$ \\
\hline RACR5 & $\begin{array}{l}\text { Uma avaliação focada na origem da acroleína merece atenção, investigando a } \\
\text { influência da concentração dos precursores e o papel da fermentação na } \\
\text { formação do aldeído, além da avaliação da possível contaminação ambiental } \\
\text { das uvas durante o cultivo. }\end{array}$ \\
\hline RACR6 & $\begin{array}{l}\text { Esta pesquisa teoricamente confirma a hipótese de que informações prévias } \\
\text { sobre a produção de leite, principalmente as marcas, levam à decisão de } \\
\text { comprar leite fluido, especialmente no caso das mulheres. O preço e a } \\
\text { disponibilidade do produto são restrições complementares. }\end{array}$ \\
\hline
\end{tabular}

Ao nos analisarmos as Tabelas 5 e 6, deparamo-nos com mais dois trechos (em destaque negrito) que apresentam, ao mesmo tempo, mais de um Movimento. Em RACR1, por exemplo, o trecho "os modelos que utilizam o produto LW não são recomendados. O modelo $L A=0,5482 \mathrm{~W} 2+0,0680 \mathrm{~W}\left(R^{2}=0,9867\right)$ é adequado para a estimação de área foliar de abobrinha 'Brasileirinha'” identificamos dois Movimentos: M4 e M5. O mesmo se repete no resumo RACR4, no trecho "o milho ainda imaturo pode estar infectado por Fusarium spp. e não deve, também, ser administrado aos equinos". Ambos os trechos comportam esses dois Movimentos, pois, ao mesmo tempo em que apresentam alguns resultados do trabalho, também discutem certos pontos da pesquisa.

A partir de exemplos como os recém citados, podemos concluir que os resumos não apresentam sempre Movimentos lineares, uma vez que os Movimentos podem se apresentam 
intercalados, principalmente nos trechos em que encontramos a apresentação dos objetivos e os resultados de pesquisa. Ambos os Movimentos, assim como a disposição das informações, estão baseados no propósito comunicativo desses resumos, fato que torna relevante a pesquisa do meio de circulação e de produção desse gênero.

A seguir, fazemos algumas considerações para finalizar este trabalho.

\section{CONSIDERAÇÕES FINAIS}

Primeiramente, o objetivo desta pesquisa é identificar como se dá a organização do gênero resumo acadêmico na área das Ciências Agrárias, isto é, seus movimentos retóricos estruturantes, realizamos a análise de um corpus formado por resumos acadêmicos de artigos da revista periódica Ciência Rural, que é um dos periódicos científicos mais bem conceituados entre as Ciências Agrárias. Faz-se necessário destacar aqui que, ao longo deste trabalho, percebemos que seria mais válido focarmos na organização do gênero resumo a partir da produção textual de autores-pesquisadores gaúchos vinculados às Ciências Agrárias. Desse modo, nossa análise não foi constituída e limitada a simples deduções, pois, conforme Bazerman (2009), cada pessoa tem uma recepção de gênero muito distinta da outra, assim como posições e atitudes. Assim, nossa ferramenta analítica foi baseada no esquema proposto por Motta-Roth e Hendges (2010).

O gênero resumo acadêmico, nesse contexto de investigação - resumos acadêmicos escritos por autores-pesquisadores gaúchos da área das Ciências Agrárias -, mostrou-se intrinsicamente relacionado ao seu contexto de produção e circulação. Sendo assim, com base nos dados obtidos, podemos destacar que os autores dos resumos acadêmicos analisados não seguem, no sentido literal, uma lineariedade na construção do gênero resumo acadêmico, de modo que algumas passagens fazem referência a mais de um Movimento retórico, conforme discutido nas seções anteriores. Concomitantemente, podemos destacar que: os Movimentos apresentar pesquisa (M2) e sumarizar resultados (M4) aparecem em todos os exemplares; enquanto o Movimento situar pesquisa é o menos recorrente. Nesse sentido, de acordo com os Submovimentos do Movimento 1 (M1 - Situar pesquisa), o destaque é atribuído a generalizações do tópico. No Movimento 2 (M2 - Apresentar pesquisa), a apresentação dos principais objetivos do trabalho se mostrou presente em todos os resumos. 
Dessa forma, podemos contrastar os resultados do gênero resumo acadêmico na área das Ciências Agrárias com a análise estrutural retomada em 2010 por Motta-Roth e Hendges nas disciplinas de Economia, Linguística e Química. As autoras reorganizam uma estrutura esquemática do gênero de modo que acabam agregando diferentes áreas além daquelas que foram base para a sua pesquisa (MOTTA-ROTH; HENDGES, 2010). Considerando os critérios metodológicos definidos, observamos que nos resumos de autores gaúchos da revista Ciência Rural, do volume 49, números 3 e 4, o propósito comunicativo está vinculado com a natureza objetiva desses resumos, assim como a descrição de resultados.

Outro fator conclusivo deste trabalho é a essencialidade em ampliar estudos nesse contexto de produção acadêmica, de modo a se obterem maiores informações do modo de escrita desse público, os autores-pesquisadores das Ciências Rurais, visto que os trabalhos teóricos existentes que analisam a produção acadêmica voltam-se, na maioria das vezes, apenas para análises das produções das áreas de Linguística e Literatura, quando muito das Exatas (Química, por exemplo). Essa poderia ser uma temática de pesquisa para trabalhos futuros na área de Letras/Linguística, uma vez que, para compreender melhor o gênero, é preciso adentrar o contexto, pois é preciso pensar o funcionamento de cada pesquisa, o modo como cada uma delas é organizada para então pensar quais são os movimentos presentes ou não nos resumos. Além disso, é necessário, em pesquisas futuras, realizar comparações entre trabalhos de uma mesma seção (seção Produção de Cultura, por exemplo). Isso possibilitaria identificar se a realização ou não de cada um dos Movimentos ou Submovimentos é padrão ou não em apenas uma ou em todas as seções (Produção de Cultura, Tecnologia de Alimento, Patologia, etc.).

\section{REFERÊNCIAS}

ASKEHAVE, I.; SWALES J. M. Genre identification and communicative purpose: a problem and a possible solution. Applied Linguistics, v. 22, n. 2, 2001.

BAKHTIN, M. Os gêneros do discurso. In: A estética da criação verbal. São Paulo: Martins Fontes, 2003.

BAZERMAN, C. Gêneros textuais, tipificação e interação. Orgs. Angela Paiva Dionízio. Trad. Judith C. Hoffnagel. 3ed. São Paulo: Cortez, 2009. 
BHATIA, V. K. Analysing genre: language use in professional settings. London: Longman, 1993.

BIASI-RODRIGUES, B. O gênero resumo: uma prática discursiva na comunidade acadêmica. In: BIASI-RODRIGUES, B.; ARAÚJO, J. C.; SOUSA, S. C. T. Gêneros textuais e comunidades discursivas: um diálogo com Jonh Swales. Belo Horizonte: Autêntica Editora, 2009.

MARTIN, J. R. Language, register and genre. In: CHRISTIE, F. Children writing: Reader. Australia: Deaking University Press, 1985.

MILLER C. R. Genre as social action, Quarterly Journal of Speech, v. 70, n. 2, 1984. p. 151-167. Disponível em: < https://www.tandfonline.com/doi/abs/10.1080/00335638409383686>. Acesso em: mai. 2019.

MOTTA-ROTH, D.; HENDGES, G. Abstract/resumo acadêmico. In: Produção textual na universidade. São Paulo: Parábola Editorial, 2010. p. 151-162.

SANTOS, M. B. Academic abstracts: a genre analysis. 1995. 119f. Dissertação (Mestrado em Letras/Inglês) - Universidade Federal de Santa Catarina, Florianópolis, 1995.

SWALES, J. M. Genre analysis: English in academic and researching settings. Cambridge: Cambridge University Press, 1990.

Recebido em 21 de abril de 2020.

Aprovado em 06 de outubro de 2020. 